\title{
The Alps Vegetation Database - a geo-referenced community-level archive of all terrestrial plants occurring in the Alps
}

\author{
Jonathan Lenoir, Jens-Christian Svenning, Stefan Dullinger, Harald Pauli, Wolfgang \\ Willner, Antoine Guisan, Pascal Vittoz, Thomas Wohlgemuth, Niklaus Zimmermann \& \\ Jean-Claude Gégout
}

\begin{abstract}
Mountain ranges are biodiversity hotspots worldwide and provide refuge to many organisms under contemporary climate change. Gathering field information on mountain biodiversity over time is of primary importance to understand the response of biotic communities to climate changes. For plants, several long-term observation sites and networks of mountain biodiversity are emerging worldwide to gather field data and monitor altitudinal range shifts and community composition changes under contemporary climate change. Most of these monitoring sites, however, focus on alpine ecosystems and mountain summits, such as the global observation research initiative in alpine environments (GLORIA). Here we describe the Alps Vegetation Database, a comprehensive communitylevel archive (GIVD ID EU-00-014) which aims at compiling all available geo-referenced vegetation plots from lowland forests to alpine grasslands across the greatest mountain range in Europe: the Alps. This research initiative was funded between 2008 and 2011 by the Danish Council for Independent Research and was part of a larger project to compare cross-scale plant community structure between the Alps and the Scandes. The Alps Vegetation Database currently harbours 35,731 geo-referenced vegetation plots and 5,023 valid taxa across Mediterranean, temperate and alpine environments. The data are mainly used by the main contributors of the Alps Vegetation Database in an ecoinformatics approach to test hypotheses related to plant macroecology and biogeography, but external proposals for joint collaborations are welcome.
\end{abstract}

Keywords: biogeography; community structure; diversity; ecoinformatics; macroecology; mountain ecology; species distribution.

\section{The Alps Vegetation Database}

Scope: The working group of the Alps Vegetation Database seeks to gather geo-referenced vegetation-plot data of all terrestrial plant communities occurring in the Alps (Austria, France, Germany, Italy, Liechtenstein, Monaco, Slovenia and Switzerland) from lowland forests to alpine grasslands. The Alps Vegetation Database has a strong focus on vascular plants though co-occurence data on bryophytes and lichens are welcome.

Status: completed and continuing Period: 1900-2009

Database manager(s): Jonathan Lenoir (lenoir.john@gmail.com); Jens-Christian Svenning (svenning@biology.au.dk)

Owner: (private)

Web address: [NA]

Availability: according to a specific agreement

Database format(s): TURBOVEG

Online upload: no Online search: no

Export format(s): TURBOVEG, MS Access, Excel, CSV file, plain text

Publication: None

Plot type(s): normal plots; nested plots; time series

Plot-size range: $0.05-1250 \mathrm{~m}^{2}$

Non-overlapping plots: 24,474

Total plot observations: 35,731

Estimate of existing plots: [NA]

Completeness: [NA]

Number of sources: 12

Countries: AT: $18.8 \%$; $\mathrm{CH}: 48.9 \%$; FR: $32.3 \%$

Forest: $59 \%$ - Non-forest: aquatic: $0 \%$; semi-aquatic: 0\%; arctic-alpine: [NA]; natural: [NA]; semi-natural: [NA]; anthropogenic: [NA]

Guilds: all vascular plants: $100 \%$; bryophytes (terricolous or aquatic): $2 \%$; lichens (terricolous or aquatic): $0 \%$

Environmental data: altitude: $99 \%$; slope aspect: $60 \%$; slope inclination: $62 \%$; soil depth: $0 \%$; soil pH: $7 \%$

Performance measure(s): presence/absence only: $3 \%$; cover: $97 \%$

Geographic localisation: GPS coordinates (precision $25 \mathrm{~m}$ or less): $8 \%$; point coordinates less precise than GPS, up to $1 \mathrm{~km}$ : $89 \%$; small grid (not coarser than $10 \mathrm{~km}$ ): $3 \%$

Sampling periods: < 1919: 0.1\%; 1920-1929: 0.1\%; 1930-1939: 1.3\%; 1940-1949: 1.3\%; 1950-1959: 3.4\%; 1960-1969: 8.0\%; 1970-1979: 11.5\%; 1980-1989: 16.5\%; 1990-1999: 33.6\%; 2000-2009: 8.1\%; unknown: $16.3 \%$

Information as of 2012-07-12; further details and future updates available from http://www.givd.info/ID/EU-00-014 
Jonathan Lenoir* (lenoir.john@gmail.com)

UR “Ecologie et Dynamique des Systèmes Anthropisés" (EA 4698), Plant Biodiversity Lab, Jules Verne University of Picardie, 1 Rue des Louvels, 80037 Amiens, FRANCE

Jens-Christian Svenning (svenning@biology.au.dk)

Ecoinformatics \& Biodiversity Group,Department of Bioscience, Aarhus University, Ny Munkegade 114, 8000 Aarhus, DENMARK

Stefan Dullinger (stefan.dullinger@univie.ac.at), Harald Pauli (harald.pauli@univie.ac.at)

Department of Conservation Biology, University of Vienna, Rennweg 14, 1030 Vienna, AUSTRIA

Wolfgang Willner (wolfgang.willner@vinca.at)

Vienna Institute for Nature Conservation and Analyses, Giessergasse 6/7, 1090 Vienna, AUSTRIA

Antoine Guisan (antoine.guisan@unil.ch), Pascal Vittoz (pascal.vittoz@unil.ch)

Department of Ecology and Evolution, University of Lausanne, Biophore, 1015 Lausanne, SWITZERLAND

Thomas Wohlgemuth (thomas.wohlgemuth@wsl.ch), Niklaus Zimmermann (niklaus.zimmermann@wsl.ch)

Swiss Federal Institute for Forest, Snow and Landscape Research (WSL), Zürcherstr. 111, 8903 Birmensdorf, SWITZERLAND

Jean-Claude Gégout (jean-claude.gegout@agroparistech.fr)

AgroParisTech-ENGREF, UMR1092, Laboratoire d'Etude des Ressources Forêt-Bois (LERFoB), 14 rue Girardet, 54000 Nancy, FRANCE

*Corresponding author 